\title{
Empirical Analysis of Demand for Residential Electricity in Beijing: An Application of Co-Integration Techniques and Error-Correction Model
}

\author{
Fuwei Zhang ${ }^{1,}$ a , Wenjing Wang ${ }^{2, \mathrm{~b}}$, Hongjie Ding ${ }^{3, \mathrm{c}}$, Zhiting Wu ${ }^{3, \mathrm{~d}}$ \\ and Yan Yan ${ }^{3, e}$ \\ ${ }^{1}$ Zhang, Fuwei North China Electric Power University \\ ${ }^{2}$ Wang, Wenjing North China Electric Power University \\ ${ }^{3}$ North China Electric Power University \\ azfw@ncepu.edu.cn, ${ }^{b} 807694235 @ q q . c o m,{ }^{c} 332471509 @ q q . c o m ;$ \\ d503393317@qq.com; ${ }^{2} 77398906 @ q q . c o m$
}

\begin{abstract}
This paper attempts to prognosis the income and price elasticity of demand for residential electric power for long-run and short-run in Beijing. Based on the annual data about residential electricity consumption during 1990-2012 in Beijing, two long-run demand function model were conducted to measure the impacts of the various factors on demand for residential electricity, to which the co-integration technical analysis was applied. Then, the error-correction model was built to estimate the corresponding price elasticity of electric, income elasticity and alternative energy price elasticity. The income and price elasticities were estimated as 1.323 and -0.273 in the long run, 0.289 and 0.413 in the short run, respectively, implying that demand for residential electricity in Beijing is income-elastic and price-inelastic in the long run. Finally, some suggestions were proposed to help policy-makers to predict the effect of the income and price on the demand for residential electricity and formulate corresponding policy in future.
\end{abstract}

Keywords: demand for residential electricity, co-integration techniques, errorcorrection model, price elasticity, income elasticity

\section{Introduction}

With the rapid growth of economy, Beijing experiences the radically increase of energy consumption, particularly the increase of spending electricity. As in fig 1 and fig 2, from 1990 to 2012, total electric power consumption of Beijing is at an average growth about $8.44 \%$ per year, from 15.05 billion $\mathrm{KWh}$ to 87.43 billion KWh. While the residential energy consumption (expressed by electric power consumption) at an average growth about $6.16 \%$ per year, from 9.32 billion KWh to 34.94 billion KWh. Electricity consumption of residents at an average growth about just $13.85 \%$ per year, which is $5.41 \%$ and $7.69 \%$ higher than that of the total electricity consumption and residential energy consumption, respectively, from about 0.95 billion KWh to 16.18 billion $\mathrm{KWh}$. Furthermore, electricity consumption of residents in Beijing as a share of total electricity consumption and residential energy consumption has increased respectively from $6.31 \%$ and $10.19 \%$ in 1990 , to $18.51 \%$ and $46.28 \%$ in 2012 .Though the growth rate of electric power consumption is high, the level of electricity consumption per capita is not higer than that of the developed nations. For instance, in 2006, the electricity consumption per capital in Beijing is $611 \mathrm{KWh}$, which is lower than that of United States (4508 KWh), Japan $(2188 \mathrm{KWh})$, Germany $(2188 \mathrm{KWh})$. The proportion of residential electricity consumption accounted for the total consumption of electricity in Beijing is lower 
than that of the United States (33\%), Japan (28.1\%), and Germany (26.1\%). It can be seen that, compared with developed countries, demand for residential electricity in Beijing still have broad development prospects. Demand for residential electricity will be an important increasing particle of the total electricity consumption and the most important residential terminal energy of Beijing in the future.

The key deciding factors of demand for residential electricity in Beijing can be conclude as disposal income per capita, price of itself or alternative energy. In the period 1990 to 2012, the disposal income per capita of Beijing increased by $10 \%$ annually, from $¥ 1657.15$ to $¥ 33907.61$. Since 1990 , with the rapid development of household appliance market of Beijing, various energy consuming services by households step into market, such as air conditioners, refrigerators, microwave ovens, LCD TVS, vacuum cleaners, etc. An increase in the disposal revenue often altered consumer's preferences for energy-consuming or bigger household appliances. What's more, the supply of residential electricity is controlled by the State grid corporation possessed by the China government. Hence, the electricity price of residents has been controlled at a relative low level in order to engage in inflation and the policy of price discrimination. In 2009, for instance, the price of residential electricity in Beijing was just $¥ 0.488 / \mathrm{KWH}$, which is not higher than Korea ( $¥ 0.51 / \mathrm{KWH}$ ), America ( $¥ 0.77 / \mathrm{KWH}$ ), France ( $¥ 1.06 / \mathrm{KWH}$ ), and United Kingdom ( $¥ 1.37 / \mathrm{KWH}$ )(EIA,2009). Compared with domestic developed cities, the price of residential electricity in Beijing is still lower than that of Shanghai ( $¥$ $0.617 / \mathrm{KWH}$ ), Guangdong ( $¥ 0.61 / \mathrm{KWH}$ ), Hangzhou ( $¥ 0.538 / \mathrm{KWH}$ ). In addition, its alternated energy price has affected the residential demand for electricity in terms of cooking aspects. However, except that natural gas price is stable and environment friendly, prices of other alternated energy--liquefied gas, pipeline gas, will float with the market demand, and this will result residents being more preferred to electricity, the price of which is more stable in a long period . All in all, the constant improvement of disposal income per capita, combined with relatively low electricity price and unstable price of its alternated energy, promote the increase of demand for residential electricity.

From the environmental protection perspective, lower energy efficiency and irrational energy structure will result various environmental problems. How to formulate energy price policy and improving energy efficiency to alleviate the environment pressure must be taken into consideration by the government. Therefore, analysis of the relationship among electricity demand for residents and its main factors and estimation of the historical development of residential electricity consumption characteristics is particularly important.

There have been many studies on the demand for residential electricity (Ang et al., 1992; Holtedahl and Joutz, 2004; Filippini and Pachauri,2004; Hondroyiannis, 2004; Filippini and Pachauri, 2004; and so on.) [1-7]. But researches about the estimation of the demand for residential electric power in China are limited, particularly in Beijing. Due to data limitation, studies about demand for residential electricity in China tend to employ macro aggregate data (annual or monthly) at national or provincial level. For instance, Zheng, e t a 1 (2003) made the model that the electricity demand for residents in Beijing and take it as a function of weighing income per head, prix of power and natural gas, and temperature by using annual data from 1990 to 2000 [8]. Cheng (2007) used annual data at provincial level to elaborate the influence of the urbanization on residential electric power consumption in Chengdu province by co-integration technique [9]. And Yu,et al. (2009) used panel data to analyze the electricity consumption characteristics of 7 typical cities in China at different income levels[10]. The limitation of previous studies about China lies in that the data span and the estimation of short-run 
characteristics of residential electricity consumption is limited, and the introduction of natural gas as the only substitute source of energy is not much reas onable for the existing of various substitute source of energy in a long period.

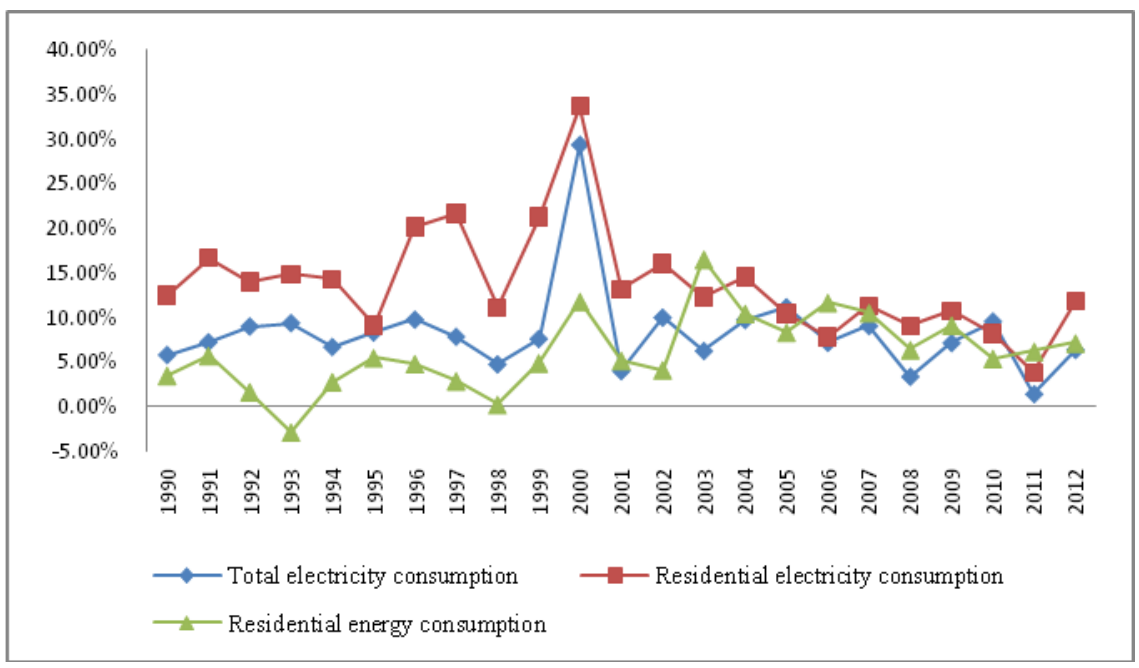

Figure 1. Growth Rate of Total Electricity Consumption, Residential Electricity and Energy Consumption 1990-2012. Source: Beijing Statistical Yearbook (1990-2013)

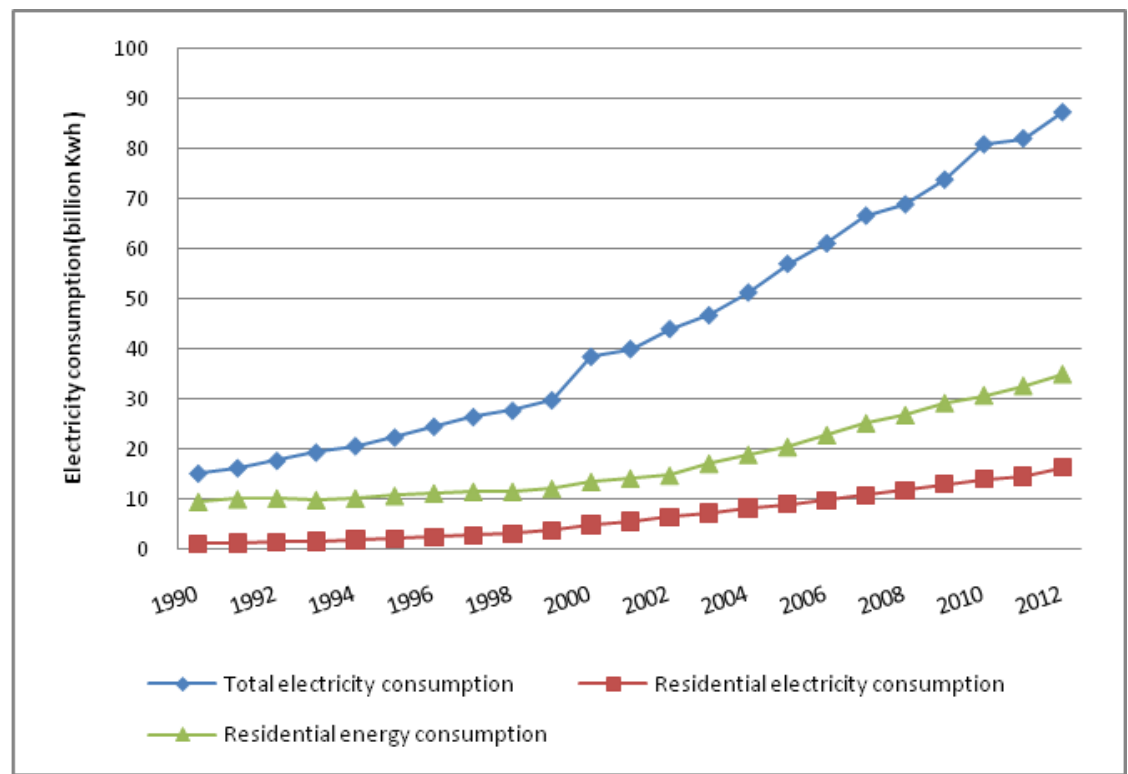

Figure 2. Consumption of Total Electricity, Residential Electricity and Energy 1990-2012. Source: Beijing Statistical Yearbook (1990-2013)

This paper use panel data to predict demand for electricity elaticities of residents in Beijing. The data was gathered by searching for Statistics Yearbook about annual residential electric power consumption of residents in Beijing during the year of 1990-2012. While the price and income variable had collected were nominal values, these variables can be converted to the actual value after excluding inflation. In this paper, the disposable income was adjusted by using the consumer price index, and electricity and alternative energy price were adjusted by using hydro fuel prices indexes. In previous studies, the price of natural gas was usually treated as the price of substitute source of energy. In this study, constrained by data limitation, its 
alternated energy price is processed as a kind of comprehensive price of its alternated energy by converting the prices of the involved alternated energy into the uniform price of standard coal according to the standard coal reference coefficient of energy published in 《China energy statistical yearbook》, which is the first-time application in the studies on electric power demand for residents in China.

The purpose of this study was to forecast the long-run and short-run income and price elasticity of residential demand for electricity in Beijing by co-integration techniques and vector error-correction model. Based on the different treatments of price factors, this study builds two models, which is also the first first-time application in the researches on electricity demand of residents in China. In model 1 , despite of the disposable income for per capita, the comprehensive price of its alternated energy and the electricity price are expressed as independent variables. And in model 2, the price factor is expressed as relative price. From the energy policy making and residential electricity consumption promoting points of view, this process has more practical significance. This method in relative price was proposed by Been stock et al., and put into use by Nara yan and Smyth, Narayan and Smyth [11-12]. On the basis of the two models, the corresponding error correction model is estimated, and results showed that there were long-term and short-term and stable relations, embodied as a function, among influence factors and demand for residential electricity in Beijing.

The remaining sections of this article are constituted as this: Part 2 shows the review of the literature in the basis of analyzing the demand elasticity of electric power of residents. Part 3 introduces the patterns, models and data used in this paper. Part 4 explains the methodology. The empirical results are showed in Part 5. Certain conclusive remarks in the final part are made.

\section{Literature review}

Empirical studies on the elasticity of demand for residential electricity have drawled enough attention both in developed countries and in developing countries, including Singapore, Colombia, Tiwan, India, Greece, Netherlands, Australia, Namibia, Turkish, G7 countries, the United States, South Africa, Japan [13-16]. The empirical findings of the above studies can be summarized as follow. Firstly, the negative price elasticity of demand implies that the increment of the energy prices on the citizenry will decrease the demand for residential electricity. In addition, the demand for electric power of residents is price-inelastic, that signifies a low sensitivity of demand for residential electricity to changes in the electricity price of residents. Secondly, the income elasticity is positive, which means that an increase in the income will result the increase in demand for residential electricity to some extent. As for the sensitivity to demand for residential electricity, income elasticity can be greater than one, or less than one. Thirdly, according to Donatos and Mergos (1991), De Vita et al., and Narayan and Smyth, long-run price and income elasticity are more elastic than the short-run ones when all of them are statistical significant [17]. Fourthly, electricity price often have short-run impact on the need for residential electricity, however The per capita income and the price of electricity influence on demand for residential electricity.

In the existing studies, besides two main explanatory variables of electricity price and income per capita, the impact of other deciding factors on the demand for residential electricity are often examined, such as alternated energy price, quantity and home appliances price, population, family scale, dwelling size, and temperature which affecting household preferences. Due to data limitation, the vast majority of literature can only introduce one or a few factors in the model. Given that electricity consuming appliances have different consumption characteristics, which indicates 
that the simple sum of electric appliances will lose the practical significance, the quantity of household electrical appliances are usually excluded. For example, Blázquez, et al., (2012) introduced price of natural gas, population, living area per capita, and temperature into the model when established Spanish residents electricity demand model[18]. Holtedahl and Joutz (2004) took the disposable income per household, population growth, electricity price and urbanization level into consideration while predicting The electrical demand for residents in Taiwan. Yoo et al., expressed the residential electricity consumption in Seoul as a function of size of family, size of house, dummy for having a plasma display panel television, dummy for having an air conditioner, and the income per household [19]. Dilaver and Hunt considered electrical demand for residents in Turkish, and regarded it as a function that consumer of household total final consumption expenditure and electricity price of residents. Donatos and Mergos make models of need for residential electricity in Greece and regard it as a function of disposable per capita income, price of electric power, population, price of its alternated energy, LPG, temperature, sales of electrical appliances, consumers' quantum and Diesel prices.

Of the models adopted in literatures on demand for residential electricity, cointegration technique is the most widely used. Ziramba and Narayan and Smyth used bounds checking out approach to co-integration to analyze the residential demand for electricity in Australia and South Africa, respectively. Nakajima and Narayana and Smyth adopted the panel co-integration techniques to model the demand for residential electricity of Japan and G7 countries, respectively. Hondro yiannis and Dergiades and Tsoulfidis used the ARDL approach to co-integration to separately estimate the residential demand for electricity in Australia and the United States. Holtedahl and Joutz and Halvorsen and Larsenmade made use of co-integration and error correction procedures to estimate residential electricity elasticity of Tiwan and Norwegian, respectively[20]. Besides, the co-integration technique, other models, such as partial-adjustment model (Blazquez et al.,), bivariate del (Yoo et al.,), structural time series model (Dilaever and Hunt), are also introduced in studies.

Data employed in literature can be classified into time sequence data, panel data and cross-sectional data, and all of the three kinds of data are macro-level or microlevel. Holtedahl and Joutz, Hondroyiannis, and Dergades and Tsoufidis employed macro time sequence data at national or provincial level to estimate the residential demand for electricity in Tiwan, Australia, and the United States, respectively. Nakajima (2010), Narayana and Smyth, and Blazquez, et al., used panel data at national or provincial level when analyzed the need for electric power for residents in Japan, G7 countries, and Spain, respectively. Studies that employed micro-level data in survey can introduce more variables to seek more family features. For example, Yoo et al., applying data in survey at household level in Seoul, made model in demand for electric power for residents as a function of main influencing factors such as family scale, dwelling scale, revenue of per family, electricity power price, etc., and Filipofpini and Pachaeruri, taking data of Swiss investigation at household standard, model electricity need for residents, and it is regarded as a function of electricity price, prices of alternated resources, kerosene, LPG, income per capita, dwelling size, family scale and a variety of pseudo variables to find differences of household [21].

\section{Model and Data}

Based on the different treatments of price variable, we propose two patterns, Where the electricity demand is the most close to the standard level, based on the existing literature and data. The difference between the two models lies in the 
expression of price variable. In model 1, besides the disposable income of per capita, the electric power price and comprehensive price of its alternated energy are introduced as independent variables, which This is the most common way to measure the alternative price in the literature. In model 2 , the price variable is a relative variable which is expressed by the ratio of electricity price to the comprehensive price of its alternated energy. The definition of two models has three advances. Firstly, it can distinguish the relationship between household electricity demand and electricity price as well as the price of alternative energy sources. Secondly, it can estimate the magnitude of the effect of electricity price versus the comprehensive price of its alternated energy on demand for residential electricity. Thirdly, introducing a relative price variable into the model (Model 2) can reduce one or more exogenous variables. The form of the model is as follows:

Model 1:

Model 2:

$$
\ln E C_{t}=\alpha_{0}+\alpha_{1} \ln Y_{t}+\alpha_{2} \ln E P_{t}+\alpha_{3} \ln S P+\varepsilon_{t}
$$

$$
\ln E C_{t}=\beta_{0}+\beta_{1} \ln Y_{t}+\beta_{2} \ln R P_{t}+\mu_{t}
$$

The dependent variable, $\ln E C$, is the natural $\log$ of Residents per capita electric power consumption (KWh per capita). In both models $\ln Y$ is the natural $\log$ of the average per capita disposable revenue. Meanwhile, in Model 1, lnEP, the natural log of the electricity price of residents ( $¥ \mathrm{RMB} / \mathrm{kWh}$ ), and the proleptic sign of it is negative. $\operatorname{Ln} S P$ is the natural $\log$ of the comprehensive price of involved substitute source of energy ( $¥ \mathrm{RMB} / \mathrm{kgce}$ ). In addition, $\ln R P$ represents the natural log of the electricity price of residents to the comprehensive price of its alternated energy, and it is expected to show a negative correlation with the amount of electric power consumption in Model 2.

Finally, ${ }^{\varepsilon_{t}}$ and $\mu_{t}$ are residual errors supposed to be white noise and normally distributed. Our motivation to introduce the converted price of the involved alternative energy sources as the comprehensive price of its alternated energy lies in the fact that though all the involved substitute source of energy (natural gas, liquefied petroleum gas, coal, pipe-line gas) always had influences on the residential electricity consumption over the period 1990-2012, the data of them were unavailable completely (Pipe-line gas was widely used by residents since 1959, but its supply ended up in 2007. The development period of natural gas began is from 1997 to present. The prices of liquefied petroleum gas always fluctuate according to demand.). Thus, introducing the converted price of the involved substitute source of energy as the comprehensive price of its alternated energy is in more practical in estimating the residential electricity consumption. The converted price of the involved alternative energy is calculated by dividing the residential fuel expenditure per capita by calorific value per capita. The total calorific value per capita, as the substitute demand for electricity, is converted by the involved substitute source of energy (natural gas, liquefied petroleum gas, coal, pipe-line gas) according to the standard coal reference coefficient of energy published in 《China energy statistical yearbook》.

In the empirical analysis, there is a long-term relationship between our test variables. We can also use error correction model to calculate the short-term dynamic variables. This is based on following steps. Firstly, to avoid the spurious regression, we need to verify the order of integration of the variables, for the result of co-integration tests are valid only if the variables have the same order of integration. Secondly, we need to test for co-integration among variables (Eq. (1)) by using the Engle-Grange co-integration test proposed by Engle and Grange (1987)[22]. If there is co-integration among these variables, the short-term ECM 
model that had one period lagged error correction should be established. And it can measure the speed that the system returns to the balance after receiving the shock.

Annual time series data was used at provincial level during year 1990 to 2012.All data are obtained from the Beijing statistical yearbook and Cities of New China for 50 years. Since the disposable income of per capita and electric power price and the comprehensive price of alternative energy is a nominal value, we need to deflate them by the consumer price index, electricity and fuel price index respectively to eliminate the influence of inflation.

\section{Methodology}

\subsection{Unit root test}

Before doing co-integration regression, testing the sequence of integration is necessary. The purpose of the ADF test is to test whether time series of the variables introduced into the model are stationary. If they are non-stationary, we need to determine the order of integration of variables. Only when all the variables have the same order of integration can the various co-integration tests be valid. This study adopts the ADF test (Augment Dickey-Fuller Unit Root Test) proposed by Dickey and Fuller (1979) on the basis of DF test in order to eliminate the autocorrelation in the residuals and the limitation of time trends. The determination of the order of integration of all variables, including $\ln E C, \ln E P, \operatorname{Ln} S P, \ln R P$, is based on the following regression:

$$
\begin{gathered}
\Delta y_{t}=\rho y_{t-1}+\sum_{i=1}^{p} \gamma_{i} \Delta y_{t-1}+u_{t} \\
\Delta^{2} y_{t}=\rho \Delta y_{t-1}+\sum_{i=1}^{p} \gamma_{i} \Delta^{2} y_{t-1}+u_{t} \\
\Delta^{3} y_{t}=\rho \Delta^{2} y_{t-1}+\sum_{i=1}^{p} \gamma_{i} \Delta^{3} y_{t-1}+u_{t}
\end{gathered}
$$

$y_{t}, \Delta y_{t}, \Delta^{2} y_{t}, \Delta^{3} y_{t}$ are the time series of all variables of level, first-difference, second-difference, third-difference, respectively. The letter $p$ is the maximum lagged differences of the autoregression sum of the dependent variables. The determination of $p$ value depends on two principles: (1) In order to reduce the degree of freedom, the $p$ value should be low as much as possible.(2)In order to eliminate the autocorrelation in the residuals. Drift and trend items can also be added into the above regression according to trend graph and autocorrelation graph.

The null hypothesis of the above ADF test is:

$\mathrm{H}_{0}: \gamma=0$.It indicates that there exists no unit root in the variables. And the alternative is that there exists a unit root in the variables. That is, $\mathrm{H}_{1}: \gamma<0$.

The statistics of $\mathrm{ADF}$ test is that: $\mathrm{ADF}=t_{\rho}$. For $\mathrm{Eqs}(3)$, if $t_{\rho}$ is lower than the Mackinnon critical value, $y_{t}$ is stationary. For Eqs(4), if $t_{\rho}$ is lower than the Mackinnon critical value, $\Delta y_{t}$ is stationary $y_{t}$ is $I(1)$. For Eqs(5), if $t_{\rho}$ is lower than the Mackinnon critical value, $\Delta^{2} y_{t}$ are stationary, $y_{t}$ is $I(2)$.

\subsection{Co-integration test}

Supposing that consumers' electric power consumption and its primary determinant are integrated of the same order, examining whether there exists a longrun equilibrium relationship among all variables is of great significance. We test for the co-integration by the Engle-Grange (EG) co-integration test that based on the unbalanced residual $\left(e_{t}\right)$ proposed by Engle-Grange(1987). The principle of EG cointegration test is to examine whether the residual series based on model 1 and 2 are stationary. For model 1, the expression of residual series is: 


$$
e_{t}^{1}=\ln E C_{t}-\alpha_{0}-\alpha_{1} \ln Y_{t}-\alpha_{2} \ln E P_{t}-\alpha_{3} \ln S P
$$

For model 2, the expression of residual series is:

$$
e_{t}^{2}=\ln E C_{t}-\beta_{0}-\beta_{1} \ln Y_{t}-\beta_{2} \ln R P_{t}
$$

The EG co-integration test expression is:

$$
\Delta e_{t}=\hat{\rho} e_{t-1}+\varepsilon_{t}
$$

If $\varepsilon_{t}$ is autocorrelated, the co-integration test should be switch to following Augment Engle-Grange co-integration test (AEG):

$$
\Delta e_{t}=\hat{\rho} e_{t-1}+\sum_{i=1}^{p} \hat{r}_{i} \Delta e_{t-1}+\varepsilon_{t}
$$

The test statistics of $\hat{\rho}\left(t^{*}\right)$ need to be compared with the critical response surface function of McKinnon co-integration test $C_{\alpha}$. If $t^{*}<C_{\alpha}$, the residual series based on $\mathrm{Eq}(6)$ and $\mathrm{Eq}(7)$ are stationary, which indicates that the null hypothesis of no co-integration can be rejected.

\section{Empirical results}

The ADF unit root test results and values of the probability are showed in Table 1. And results indicate that all variables are integrated of order one (I (1)). Whereas the first differences are integrated of order zero, I (0). We cannot turn down the unit root Zero assumption of the whole five variables towards to the log-levels at the 5\% level. But we can refuse the unit root null hypothesis of the first difference of all the five variables for the log-levels at the significant level of $1 \%$.

After built up five variables, it is of great importance to check whether there is a long-tern relationship between electric power consumption of residents and main deciding factors employing Engle-Grange co-integration test proposed by Engle and Grange(1987). The results co-integration test are reported in Table 2. The results suggest that there is a co-integration relationship among variables for both models. For both models, the Engle-Granger test statistics t value of residual is -4.47 and 4.12 , respectively, and both are less than the threshold of McKinnon co-integration test $(\alpha=0.05)$ of -3.94 .

The long-run elasticity of demand for residential electricity based on Model 1 and 2 are estimated by estimator of OLS. The short-run flexibility is also estimated to measure the adjusted speed of electric power demand while the system is shocked(s). The long-run estimation and diagnostic test results for Model 1 and Model 2 are showed in Table 3 and Table 4, respectively. From the long-term estimation outcomes, it is suggested that the significant level of all variables will be better in $10 \%$ or above $10 \%$ from a statistical perspective. The diagnostic test results for model 1 and 2 show that, at 5\% level or better, both models all hypothesis test, including conditional heteroscedasticity test, serial correlation test and normality test, which indicates that there exist no first-order and higher-order autocorrelation and conditional heteroscedasticity in the residuals of both models, and residuals of model are approximately obey the normal distribution. Thus estimate the results of both long-run models are believable.

The estimation outcomes of the short-term models are reported in table 5 and table 6 on the basis of model 1 and 2, respectively. The one period lagged error term is statistically significant at 5\% level with a negative sign in both of the short-run models, implying that the electric power consumption for residents will revert to its equivalents after a shock to the system. The coefficient of the one period lagged error term, reflecting the adjusting speed, is between -0.37 and -0.53 , which indicates an increase in the electric power price will results the households switching towards using other alternative energy, such as natural gas, liquefied 
petroleum gas, coal, pipeline gas, and even when the electricity price turn to the original level or reduce. After it takes households 0.37 to 0.53 year, they convert to using electric power.

The threshold response surface function of McKinnon co-integration test is $C_{\alpha}$. $C_{\alpha}=\varphi_{\infty}+\varphi_{1} n^{-1}+\varphi_{2} n^{-2}, \alpha$ is the significance level; the level of $\varphi_{\infty}, \varphi_{1}, \varphi_{2}$ can be queried in the relevant data table of the threshold response surface function of McKinnon co-integration test simulated by Ronald I. McKinnon(1991)

Table 1. Unit Root Test Results

\begin{tabular}{c|c|c}
\hline Variables & ADF-statistics & Probability value \\
\hline $\operatorname{Ln} E C$ & -1.193 & 0.251 \\
$\Delta \ln E C$ & $-3.277^{* * * *}$ & 0.005 \\
$\operatorname{Ln} Y$ & -0.881 & 0.396 \\
$\Delta \ln Y$ & $-3.307^{* * * *}$ & 0.006 \\
$\operatorname{Ln} E P$ & -1.285 & 0.217 \\
$\Delta \ln E P$ & $-4.822^{* * *}$ & 0.000 \\
$\operatorname{Ln} S P$ & -1.525 & 0.936 \\
$\Delta \ln S P$ & $-3.307^{* * *}$ & 0.006 \\
$\operatorname{Ln} R P$ & -1.336 & 0.701 \\
$\Delta \ln R P$ & $-5.334^{* * *}$ & 0.000 \\
\hline
\end{tabular}

Note: ${ }^{* * *}$ Denotes statistical significant at the $1 \%$ level

Table 2. EG co-Integration Test Results

\begin{tabular}{c|c|c|c}
\hline Variables & $\begin{array}{c}\text { ADF- } \\
\text { statistics }\end{array}$ & $\begin{array}{c}\text { Mackinnon critical } \\
\text { value }\end{array}$ & $\begin{array}{c}\text { Order of } \\
\text { integration }\end{array}$ \\
\hline$e_{t}^{1}$ & $4.473^{* *}$ & -3.939 & $\mathrm{I}(0)$ \\
$e_{t}^{2}$ & $4.124^{* *}$ & -3.939 & $\mathrm{I}(0)$ \\
\hline
\end{tabular}

Note: ${ }^{* *}$ Denotes statistical significant at the $1 \%$ level(5\%)

Table 3. Estimated Long-Run Coefficients for Model 1

\begin{tabular}{|c|c|c|c|}
\hline \multicolumn{4}{|c|}{ Long -run elasticity } \\
\hline Variables & Coefficient & t-statistics & Probability value \\
\hline Coeficient & -0.236 & -0.453 & 0.606 \\
\hline $\operatorname{Ln} Y$ & $1.224^{* * *}$ & 3.331 & 0.001 \\
\hline $\operatorname{Ln} E P$ & -0.273 & -0.721 & 0.472 \\
\hline $\operatorname{Ln} S P$ & $0.461^{* * *}$ & -3.044 & 0.003 \\
\hline \multicolumn{4}{|c|}{ Diagnosis } \\
\hline Variables & \multicolumn{2}{|c|}{ t-statistics } & Probability value \\
\hline $\mathrm{F}$ & \multicolumn{2}{|c|}{$1413.39^{* * * *}$} & 0.000 \\
\hline$W T_{\chi_{0.05}^{2}(9)}$ & \multicolumn{2}{|c|}{$4.113^{* *}$} & 0.000 \\
\hline$J B_{\chi_{0.05}^{2}(2)}$ & \multicolumn{2}{|c|}{$1.238^{* *}$} & 0.218 \\
\hline$Q_{\chi_{0.05}^{2}(12)}$ & \multicolumn{2}{|c|}{$16.23^{* *}$} & 0.183 \\
\hline $\mathrm{R}^{2}$ & \multicolumn{2}{|c|}{0.998} & \\
\hline DW & \multicolumn{2}{|c|}{1.95} & \\
\hline
\end{tabular}




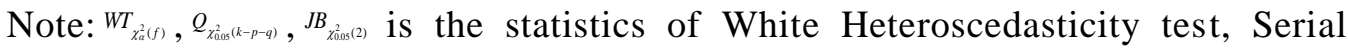
Correlation test, and Normality test, respectively, and they are all approximately obey to the chi-square distribution

$* * *(* *)$ denote statistical significance at the $1 \%$ and $5 \%$ levels, respectively.

Table 4. Estimated Long-Run Coefficients for Model 2

\begin{tabular}{c|c|c|c}
\hline \multicolumn{5}{c}{ Long -run elasticity } \\
\hline Variables & Coefficient & t-statistics & Probability value \\
\hline Coeficient & 1.764 & -0.156 & 0.876 \\
LnY & $1.421^{* * *}$ & 3.191 & 0.002 \\
LnRP & $-0.804^{* * *}$ & -4.66 & 0.000 \\
\hline \multicolumn{3}{|c}{ Diagnosis } & \multicolumn{2}{|c}{ Probability } \\
\hline \multicolumn{3}{c}{ t-statistics } & 0.00 \\
\hline Variables & $1215.67^{* * *}$ & 0.684 \\
$W T_{\chi_{0.05}^{2}(5)}$ & $3.563^{* *}$ & 0.561 \\
$J_{\chi_{0.05}^{2}(2)}$ & $2.342^{* *}$ & 0.374 \\
$Q_{\chi_{0.05}^{2}(12)}$ & $12.473^{* *}$ & \\
$\mathrm{R}^{2}$-adjust & 0.987 & \\
DW & 2.02 & \\
\hline
\end{tabular}

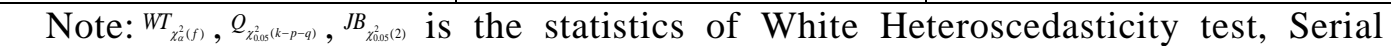
Correlation test, and Normality test, respectively, and they are all approximately obey to the chi-square distribution

$* * *(* *)$ denote statistical significance at the $1 \%$ and $5 \%$ levels, respectively.

Table 5. Error Correction Representation for Model 1

\begin{tabular}{c|c|c|c}
\hline Variables & Coefficient & t-statistics & $\begin{array}{c}\text { Probability } \\
\text { value }\end{array}$ \\
\hline Coeficient & $0.063^{* *}$ & 3.494 & 0.002 \\
$\Delta \ln Y$ & 0.232 & 0.892 & 0.372 \\
$\Delta \ln E P$ & $-0.413^{* * *}$ & -2.964 & 0.004 \\
$\Delta \ln S P$ & $0.220^{* * *}$ & -3.834 & 0.000 \\
ECT(-1) & $-0.531^{* *}$ & -2.566 & 0.012 \\
\hline
\end{tabular}

Note: ${ }^{* * *}\left({ }^{* *}\right)$ denote statistical significance at the $1 \%$ and $5 \%$ levels, respectively.

Table 6. Error Correction Representation for Model 2

\begin{tabular}{c|c|c|c}
\hline Variables & Coefficient & t-statistics & $\begin{array}{c}\text { Probability } \\
\text { value }\end{array}$ \\
\hline Coefficient & $0.126^{* * *}$ & 3.044 & 0.003 \\
$\Delta \ln Y$ & 0.344 & 1.131 & 0.260 \\
$\Delta \ln R P$ & $-0.534^{* * *}$ & -2.966 & 0.004 \\
ECT $(-1)$ & $-0.371^{* *}$ & -2.567 & 0.012 \\
\hline
\end{tabular}

Note: ${ }^{* * *}(* *)$ denote statistical significance at the $1 \%$ and $5 \%$ levels, respectively. 


\subsection{Income Elasticity of Demand}

As shown in Table 3 and 4, the long-run income elasticity of demand for residential electricity for both models have a positive symbol and are statistically significant at 5\% significance level. The long-run income elasticity is 1.224 (model 1) and 1.421 (model 2), which indicates that that an increase of $1 \%$ in disposal income of per capita increases electric power consumption for residents in the scope of $1.224 \%-1.421 \%$ in the long term by increasing the demand of more energy consuming commodities and services. The numerical value of the long-term elasticity is in the extent of former discusses for cities of China. Zheng, et al (2003) and Yang and Qi (2004) found out the long-term income resilience of electric power demand for residents in Beijing was 0.808 and 1.443, respectively. This is within the research findings of Ren, et al., who found out that the long-run income elasticity of demand for residential electricity in 23 cities of China lied between was 0.57-1.8 for urban area and 0.58-2.88 for rural area [23]. However, long-run elasticities of demand in this study is larger than that of Australia (0.41), the United States (0.271) and Japan (0.602).

As shown in Table 4 and Table 5, the long term demand income resilience is larger than the one that in the short term, and the short-run income elasticities are statistically insignificant in both models, which means that the increase of income in the short run is able to increase the utilization of existing household appliances to some extent, but its influence is limited. The short-term income for demand elasticity of residential electric power is 0.232 (Model 1) and 0.344 (Model 2). The result is analogous to Emmanuel Ziramba (2008) who predict the short-term income resilience for demand to be 0.31 in South Africa and Fiolipipini who forecast the short-term income flexibility for demand to be 0.33 in Switzerland.

\subsection{Own Price and Cross-Price Elasticity of Demand}

In the model 1 , as shown in table 3 and table 5 , the value of price elasticity of demand for residential electricity in Beijing is at -0.273 in the long term, and at 0.413 in the short term, dropping a tint that an increase of $1 \%$ in the electric power price would reduce electricity consumption of residents by around $0.273 \%$ in the long-term and $0.413 \%$ in the short term. As expected, the own price coefficients is showing a negative symbol both in short term and long terms, but are only statistically significant at 5\% level in the short term. Previous studies of cities in China have discover the own price for resilience demand in the long term be between -0.764(Sheng, 2011) and -0.253(Yang and Qi, 2004), and in the short run to be between -0.513 (Yang and $\mathrm{Qi}, 2004$ ) and -0.352(Shong, 2006). In the G7 countries, Narayana and Smyth (2007) found that the long-term residential demand price elasticity is between -4.6 and -0.3. In Switzerland, Filippini (1999) found that the long-run own price elasticity was in the range -0.3 to -0.70 , which is a bit lower. However, in the Gulf countries, the price elasticity ranges during -0.82 in Oman and -3.39 in Bahrain. Therefore, the prediction of the price resilience of electric power demand for residents in long-term is at the unhinge end of the estimate range, which were discovered in the previous researches both China and other else countries.

In model 1, the price of its alternated energy is desired positive symbol and is ant at a significance of $5 \%$ level based on statistical point of view not only in long run but also in the short run. The price elasticity of its alternated energy of demand for residential electricity in Beijing is 0.461 in the long term, and short term is 0.22 , which can be interpreted as that a $1 \%$ the increase in the price of alternative energy sources increases residential electricity consumption by $0.461 \%$ and $0.22 \%$ respectively in the long or short term. As shown in table 4 and 6 , the relative price elasticity coefficients have the proclitic positive symbol in short and long run, and 
are at a significance level of 5\% statistically. The elasticity of the relative price of demand in Beijing is -0.804 in the long run and -0.534 in the short run, respectively, implying that a $1 \%$ augment in the ratio of electric power price to the alternative energy sources price reduces electric power consumption for residents by $0.804 \%$ in the long run and $0.534 \%$ in the short run. This finding is a bit larger than that of Zheng, et al who only found that the long run relative price elasticity of demand for residential electricity in Beijing is -0.252 .

\section{Conclusion}

In this paper, it is estimated that the long-run and short-run elasticity of income, electric power price and the comprehensive price of its alternated energy for demand for residential electricity in Beijing during the period from 1990 to 2012. To achieve that, we establish two long-run models, between which the main distinction lies in that the price variable are expressed in different format, to check the existence of a long term relationship among variables involved by co-integrating techniques, and estimate two error correction models to estimate the short-run dynamics of the variables involved. The estimated income elasticity of electric power demand for residents in Beijing is between 1.224 and 1.421 in the long run, and between 0.232 and 0.344 in the short run, which means that the increase of electric power demand for residents is more sensitive to switch in income in the long term. The estimated elasticity for electricity price, comprehensive price of its alternated energy, and relative price explain the sensitivity of demand for residential electricity to changes of price. The predicted long-run and short-run elasticity for electricity price is 0.273 and 0.413 , respectively. And the long-run and short-run comprehensive price elasticity of its alternated energy is 0.461 and 0.22 , respectively. The long-run and short-run relative price elasticity is 0.804 and 0.534 , respectively.

It can be seen from the estimated three kinds of price elasticity above that the variety in electric power price and the alternative energy pose small effect on demand for residential electricity in both the long run and the short run. This can be interpreted as that, on the one hand, the electricity price of residents in Beijing, regulated by government departments, is at the low level all the year round, which lead to low sensitivity of demand for residential electricity to price changes, and, on the other hand, the proportion of the electricity consumption for cooking purposes in the residential electricity consumption becomes increasingly small with the increase of the number and types of energy consuming appliances which means that the influence of the substitute source of energy, such as natural gas and liquefied petroleum gas, is limited.

From the energy conservation and emissions reduction point of view, the estimated price elasticity of this paper can provide reference to the power sector in Beijing in making reasonable electricity price policy, so as to guide rational electricity consumption and implementing the electrical energy substitution policy in the residential living area to reduce fossil energy consumption.

The corresponding suggestion in terms of electricity price policy making are as follows: Firstly, improving the amount of the second-step and third-step power of the existing residential multi-step tariff policy can improve the sensitivity of the demand for residential electricity to electricity price so as to encourage consumers to save electricity by using the price mechanism. In addition, in order to guarantee the basic electric power demand of the special groups, such as people with disabilities, single-parent families, and the unemployed and the low-income families, the price polices should adopt the corresponding subsidy policy. The specific practices can refer to the preferential tariff of Hong Kong of charging the 
original $200 \mathrm{KWH}$ per month of the special groups or family with $40 \%$ discount and cutting electricity deposit and minimum charge, etc. Secondly, combining the existing multi-step tariff policy and time-sharing electricity price policy, the specific practices of which is dividing the 24 hours of a day into different periods to make different charging standards according to the electricity demand situation, can make full use of the different electricity price polices at different times of day to guide residents to stagger the rush hour to alleviate the pressure of the electricity load at rush hour. Thirdly, making seasonal multi-step tariff policy, which is associating the multi-step tariff policy with seasonality, can guide residents to reduce electricity consumption during peak season so as to ease the electricity supply at peak season, and achieve the energy conservation and emissions reduction and energy saving goals.

The purpose of the electrical energy substitution policy is to substitute electricity for coal, natural gas and liquefied petroleum gas in residential living area. Professor Niu had calculated the convert electricity and environmental impact value of various terminal energy of China [24]. The results showed that the substitution of electricity for the liquefied petroleum gas and coal has obvious economic and environmental benefits, and subject to the large external dependency of natural gas, the substitution of electricity for natural gas will gain obvious economic advantages benefits. At present, the fiscal subsidy standard for electricity heating user in winter in Beijing is $15 \mathrm{RMB}$ per square meter. And the crowd with subsidies is confined to the people registered residence in Beijing. To extensively implement electrical energy substitution policy, the subsidy standard should be increased, especially for the special groups, and this policy needs to cover all the population of permanent residents in Beijing.

\section{Acknowledgements}

We are grateful to the Research Base of Philosophy and Social Sciences Planning of Beijing for fund support. We also thank two anonymous referees for comments on an earlier version of the article.

\section{References}

[1] B.W. Ang, T. N. Goh and X. Q. Liu, "Demand for residential electricity in Singapore", Journal of Energy, vol. 17, no. 1, (1992), pp. 37-46.

[2] S. Balabanoff, "The dynamics of energy demand in Latin America", OPEC Review Winter, (1994), pp. 467-488.

[3] P. Holtedahl and F. Joutz, "Demand for residential electricity in Taiwan", Energy Economics, vol. 26, (2004), pp. 204-224.

[4] M. Filippini and S. Pachauri, "Elasticities of electricity demand in urban Indian households", Energy Policy, vol. 32, (2014), pp. 429-436.

[5] G. Hondroyiannis, "Estimating residential demand for electricity in Greece", Energy Economics, vol. 26, (2004), pp. 319-334.

[6] P. Berkhout, A. Ferrer-i-Carbonellb and J. Muskens, "The ex-post impact of an energy tax on household energy demand", Energy Economics, vol. 26, (2004), pp. 297-317.

[7] P. Narayan and R. Smyth, "The residential demand for electricity in Australia: an application of the bounds testing approach to co-integration", Energy Policy, vol. 33, (2005), pp. 467-474.

[8] H. Zheng, A. L. Zhang and J. K. He, "Beijing residential electricity consumption analysis", Tsinghua University (Sci\& Tech), vol. 6, (2003), pp. 815-817.

[9] K. Cheng, "Study on Empirical Analysis of Urbanization and the Residents Demand of House Electricity -A Case Study of Chengdu City", Journal of Southwestern University of Finance and Economics in China, (2007).

[10] Y. Zhang, Y. X. He, Y. Y. Jiao, W. J. Tao and S. Liu, "Urban residential power demand and forecast based on panel data models", East China electric Power, vol. 1, (2009), pp. 51-55.

[11] M. Beenstock, E. Goldin and D. Nabot, "The demand for electricity in Israel", Energy Economics, vol. 21, (1999), pp. 168-183. 
[12] P. Narayan and R. Smyth, "Electricity consumption in G7 countries: A panel co-integration analysis of residential demand elasticities", Energy Policy, vol. 35, (2007), pp. 4485-4494.

[13] G. De Vita, K. Endresen and L. C. Hunt, "An empirical analysis of energy demand in Namibia”, Energy Policy, vol. 34, (2006), pp. 3447-3463.

[14] T. Dergiades and L. Tsoulfidis, "Estimating residential demand for electricity in the United States", 1965-2006, Energy Economics, vol. 30, (2008), pp. 2722-2730.

[15] E. Ziramba, "The demand for residential electricity in South Africa", Energy Policy, vol. 36, (2008), pp. 3460-3466.

[16] T. Nakajima, "The residential demand for electricity in Japan: An examination using empirical panel analysis techniques", Journal of Asian Economics, vol. 21, (2010), pp. 412-420.

[17] G. S. Donatos and G. J. Mergos, "Residential demand for electricity: the case of Greece", Energy Economics, (1991), pp. 41-47.

[18] L. Blázquez, N. Boogen and M. Filippini, "Demand for residential electricity in Spain: New empirical evidence using aggregate data", Energy Economics, (2012), pp. 1-10.

[19] S. H. Yoo, J. H. Lee and S. J. Kwak, "Estimation of demand for residential electricity function in Seoul by correction for sample selection bias", Energy Policy, vol. 35, (2007), pp. 5702-5707.

[20] B. Halvorsen and B. M. Larsen, "Norwegian demand for residential electricity-a microeconomic assessment of the growth from 1976 to 1993", Energy Policy, vol. 35, (2001), pp. 5702-5707.

[21] M. Filippini and S. Pachauri, "Elasticities of electricity demand in urban Indian households", Energy Policy, vol. 32, (2014), pp. 429-436.

[22] R. F. Engle and C. W. J. Granger, "Co-integration and error-correction: representation, estimation and testing”, Econometrica, vol. 55, (1987), pp. 251-276.

[23] Y. M. Ren, M. Y. Zhou and L. Qian, "The Relation Between Per Capita Household Electricity Consumption and Income Per Capita", Power System Technology, vol. 32, (2008), pp. 172-175.

[24] D. X. Niu, Y. Zhang and Z. H. Gu, "Study on the substitution of electric energy in terminal energy", Modern Economy, vol. 7, no. 13, (2008), pp. 61-63. 